\title{
Defined Variables for Modular Construction Multi Project Scheduling
}

\author{
Minjung Kim ${ }^{1}$, Moonseo Park², Hyun-soo Lee ${ }^{2}$, Hosang Hyun ${ }^{3}$ and Jeonghoon Lee ${ }^{3 *}$ \\ ${ }^{1}$ M.S course Researcher, Department of Architectural Engineering, Seoul National University, \\ Korea \\ ${ }^{2}$ Professor, Department of Architectural Engineering, Seoul National University, Korea \\ ${ }^{3}$ PhD course Researcher, Department of Architectural Engineering, Seoul National University, \\ Korea \\ *Corresponding author’s e-mail: di5555@snu.ac.kr
}

\begin{abstract}
The modular construction has several advantages such as high quality of product, safe work condition and short construction duration. So, it is adopted and utilized widely to product the house buildings. Meanwhile, the modular construction is composed of manufacturing modular units in factories and erecting it on the site. In this circumstance, the scheduling of modular construction should consider timeframe of manufacturing, transport and erection process with limited resources (e.g., modular units, transporter and workers). Also, this has a characteristic generated from the environmental condition of modular construction, which share resource pool such as the productivity of factory, storage for modular units and workers. So, the concept of multi project scheduling for modular construction should be also considered. The multi project scheduling of modular construction would manage the modular construction's characteristics and diversity of projects, as a type of modular unit, quantities, and date for delivery. In this circumstance, this research preferentially performs to define variables of required resources from numerous literature reviews and expert interviews for multi project scheduling of modular construction. The authors regard that proposed variables are used for building a scheduling of multi project modular construction and suggest a framework for schedule optimization considering factory, shipping and erection process.
\end{abstract}

\section{KEYWORDS}

Modular Building Construction; Modular Units; Resource Constrained Scheduling; Multi Project Scheduling;

\section{INTRODUCTION}

The modular construction is composed of manufacturing modular units in off-site factory and erecting it on-site (Mohsen et al, 2008). A Manufacturing works in a factory should be planned to take into account the schedule of on-site construction works because those two works operate at the same time. To do this, predicting the duration of modular construction process from modular unit production in factory to transportation and on-site erection is required (Alvanchi et al, 2012). In addition, it is important that the production plan of the modular factory because the modular 
factory supplies modular unit at multiple project not only for one project. Modular unit quantity, required type and due date are different depending on each project. Therefore, scheduling of the modular factory is required to reflect the individual production process of each project (Noh, 2005). On the other hand, current scheduling method of the modular factory is same as a way that is used in the general construction industry. Compared with general construction projects, modular construction is characterized by cyclic activities that require complicated analysis (Mansooreh Moghadam, 2012). However the traditional way does not well reflect of space allocation and repetitive tasks which are essential for the modular construction scheduling (Harris, 2006; Hosein Taghaddos et al, 2010). As a result, the current scheduling is inefficient for the resource allocation of modular construction.

Researchers have conducted a study to develop a scheduling of modular construction efficiently. However, research of modular construction scheduling mainly focuses on the scheduling optimization on a certain site (Hammad et al, 2008; Mohsen et al, 2008). Considering the growing demand for modular construction buildings, modular factory manufactures and ship modular units on multiple projects. In this circumstance, it is difficult to implement scheduling optimization method in practice. Therefore, multi project scheduling of modular construction have to reflect characteristics of the individual projects as the overall process of factory manufacturing, shipping and erection of modular units.

Objective of this research is to define variables of required resources for multi project scheduling of modular construction from literature reviews and expert interviews. The results of this research can be utilized as a basis for optimized schedule of multi project of modular construction considering factory, shipping and erection process.

\section{PRELIMINARY STUDY}

\section{Previous studies for Scheduling on Modular Construction}

According to the expert interview, the scheduling method of modular construction is same as traditional construction industry. However, constrained resource is different when performing multi project of modular construction and typical construction projects to apply the scheduling method in the same way. For the typical construction project, resource is managed by each site without sharing. However, in the case of modular construction, modular units which are produced in one factory support multiple projects. Thus, modular projects that are carried out simultaneously share the resources of the modular factory (e.g, modular unit productivity, workers, storage yard). When scheduling modular construction, not only the allocation of resource, but also the requirements of each project should be considered. Modular units are to be shipped on the date determined in accordance with the client request and on-site installation progress ( $\mathrm{H}$. Taghaddos et al. 2009). In addition, each modular unit's on-site installation sequence is fixed. Next modular unit cannot proceed with the installation, before prior modular unit installation is finished.

Traditional modular construction scheduling assumes unlimited resources (Odeh, 1992; Wang, 2006; Kim, 2007) and is inefficient to reflect repetitive activities (Harris, 2006; Kim, 2007) Therefore, the existing methods are not effective to reflect the constrained resources required by the modular construction. In addition, it is difficult to optimize the resources and the due date (Mohamed et al. 2007). The re-schedule due to the scarcity of resources or delay is difficult (Hosein, 2014), so efficient way to scheduling modular construction of multi project is required. 


\section{Previous studies of Resource Constrained Multi Project Scheduling Problem}

According to Payne (1995), 90\% of projects are in the context of multiple projects. Projects are planned individually and share limited resources. Modular construction scheduling of multi project should also be based on the constrained resources (Resource Constrained Multi Project Scheduling Problem; RCMPSP)

RCMPSP has been studied by a variety of methods. Methodologies which have been researched are exact method, heuristic method and meta-heuristic method.

The numerical approach is the exact method (Mohanty and siddiq 1989; Vercellis 1994). However, it is difficult to have derived the optimal solution to handle the scheduling problem of large-scale (Deckero et al 1991; Oguz and Bala 1994). In addition, construction managers do not bother to learn the mathematical knowledge in order to use this method (Vincent. 2009).

A heuristic method determines principle of scheduling through certain criteria. This method has less computational element, so it is simple to handle. But it provides near-optimal solution and does not present a solution in alternative ways (Kumanan et al 2006; Goncalves et al 2008).

Meta-heuristic method which has been popular recently has a genetic algorithm as a representative method. The Genetic algorithm is widely used in practice related to the scheduling problem because it is easy to implement and highly reliable (Seren Tasan. 2008). In particular, genetic algorithm in RCMPSP has been recognized for its efficiency.

Optimizing scheduling of multi project has been studied in manufacturing, shipping and construction industry. Meanwhile, modular construction needs a different approach from previous research because manufacturing of factory and construction of on-site are mixed in modular construction.

However, previous research about scheduling on modular construction mainly focused on the scheduling optimization on a particular site (Hammad et al 2008; Mohsen et al 2008). Therefore, research about multi project scheduling of modular construction is relatively insufficient.

In addition, the most research of modular construction scheduling is focused on optimizing factory production of modular unit (Jeong et al. 2006; Nasereddin et al. 2007; Yu et al. 2007; Hammad et al 2008). A simulation model was proposed to improve the efficiency of on-site modular construction using a discrete event simulation (Mohsen et al. 2008). However, there is a limitation that previous studies did not handle the overall process, factory producing, shipping and installation of on-site.

Therefore, this paper defines the variables related with the multi project scheduling of modular construction.

\section{VARIABLES FOR MULTI PROJECT OF MODUALR CONSTRUCTION}

This study analysed the factors affecting modular construction scheduling of multi project for genetic algorithm methodology. Impact factors of modular construction scheduling are defined as follows, according to modular building construction process through analysis of previous studies and expert advice.

\section{Modular Factory}

In case of multi project, the factory production sequence is closely related to the factory shipping schedule that which modular unit will be transported to which site. The factor production sequence is not always exactly same as shipping schedule. It needs to consider the productivity of modular unit in the factory, the size of storage yard of modular units, actual construction site assembling sequence (Park, 2007; Abu Hammad et al, 2008). 
Even if all of modular units are produced in the same factory production line, the productivity of each type is calculated differently depending on the type and size of modular units. For example, if modular unit size is larger, more workers are required or more time is spent. Also, if modular unit size is changed from $3 \times 6 \mathrm{~m}$ to $3 \times 9 \mathrm{~m}$, factory spend some times on preparation for changing of modular unit size. Once producing modular units is completed, these modular units are moved to the storage yard in the factory. The storage yard is an open space for modular units which is kept it before shipping. Number of modular units which are contained by storage yard is depending on the size of the storage yard. The modular units are staking in a storage yard in accordance with size of storage yard and on-site construction sequence. If modular units need cure the concreted surface, keep it in the storage yard. If not or the storage yard is full, modular units could ship to the site without staking in a storage yard.

Table 1. This is a table for defining variables. It shows the variables with the modular construction process.

\begin{tabular}{|c|c|c|}
\hline Process & Variables & Contents \\
\hline \multirow{3}{*}{ Factory } & Productivity of factory & $\begin{array}{l}\text { - Productivity is different depending on } \\
\text { modular unit type and number of workers } \\
\text { - Scheduling have to reflect each productivity }\end{array}$ \\
\hline & $\begin{array}{l}\text { A sequence of producing } \\
\text { modular unit }\end{array}$ & $\begin{array}{l}\text { - A factory producing sequence affects to the } \\
\text { scheduling of modular construction }\end{array}$ \\
\hline & Storage Yard & $\begin{array}{c}\text { - Size of storage yard affects to scheduling of } \\
\text { shipping }\end{array}$ \\
\hline \multirow[b]{2}{*}{ Transport } & Number of Trailer & $\begin{array}{l}\text { - Number of trailers for modular unit } \\
\text { transport per day }\end{array}$ \\
\hline & Transit time & $\begin{array}{l}\text { - Calculate with distance from factory to site } \\
\text { and limited speed } \\
\text { - When performing multi project of modular } \\
\text { construction, distance to the site will be } \\
\text { different with each project }\end{array}$ \\
\hline \multirow{4}{*}{ Construction } & $\begin{array}{l}\text { Sequence of on-site } \\
\text { construction }\end{array}$ & $\begin{array}{l}\text { - Factory producing sequence is affected by } \\
\text { the installation sequence of on-site } \\
\text { construction }\end{array}$ \\
\hline & Modular unit type & $\begin{array}{l}\text { - Depending on the modular unit type, } \\
\text { required installation time is different }\end{array}$ \\
\hline & Number of workers & $\begin{array}{l}\text { - Calculating constructability of on-site } \\
\text { installation based on workers }\end{array}$ \\
\hline & $\begin{array}{l}\text { Quantity of modular units } \\
\text { for project }\end{array}$ & $\begin{array}{l}\text { - Depending on the project size, required } \\
\text { quantity of modular units are different }\end{array}$ \\
\hline
\end{tabular}




\section{Shipping of modular units}

The modular unit which is ready to transport is loaded on trailer depending on their size and weight. The maximum number of modular units which can be transported in a day are set in consideration of the transit time from factory to site and maximum number of trailers per day (Park, 2007; Mansooreh et al, 2012). Modular unit loading is going to be in a state of ensuring the safety of the modular unit, and the modular unit is packaged not to be affected by rainfall. A trailer which loads modular unit should be transported in compliance with the limited speed for their safety. Arrived modular units are inspected of material condition and dropped off on the site or erected directly on the trailer.

\section{Construction on-site}

The on-site installation of modular units is initiated from the steps that you can assemble the modular units after the foundation work is done on site. The number of required modular units of project is different because each project size is different. Each project plan is different, so installation sequence is different from the project (M. Mohsen et al. 2008). Each site establishes a construction schedule based on the number of modular unit installation per day in consideration of the ability of workers, equipment (e.g., crane), modular unit size (Park, 2007). On-site installation, after install the first modular unit and proceeds next modular unit construction including welding between units. Depending on the project, first floor needs joint construction between the base and the modular units.

\section{CONCLUSIONS}

Modular construction has the advantage to shorten the construction time. With the increasing demand for modular building construction, multi project is being carried out by modular factory. In this situation, modular factory takes into consideration each project's characteristics and shared resources.

This study found the parameters related to the modular construction scheduling. Optimized scheduling of multi project can be derived by using the genetic algorithm based on these variables. Workers, the storage yard size, set the number of projects can be performed by the optimization analysis. It will be more efficient for modular construction scheduling of multi project to take into account the elements which proposed in this study. Future research should be conducted based on this research results and additional research.

\section{ACKNOWLEDGEMENTS}

This research was supported by a grant (14RERP-B082884-01) from Housing Environment Research Program funded by Ministry of Land, Infrastructure and Transport of Korean government.

\section{REFERENCES}

Alvanchi, Reza Azimi, SangHyun Lee, Simaan M. AbouRizk, Paul Zubick. (2012) "Off-site construction planning using discrete event simulation”, J. Archit. Eng. 18:114-122.

Deckero, R., Winkofsky, E. P., Herbert, J., and Gagnon, R. (1991). “A decomposition approach to multi-project scheduling." European J. Operational Res., 150(1), 115-135.

Goncalves, J. F., Mendes, J. J. M., and Resende, M. G. C. (2008). "A genetic algorithm for the resource constrained multi-project scheduling problem.” Eur. J. Oper. Res., 189(3), 1171-1190. 
Hammad, A. A., Salem, O., Hastak, M., and Syal, M. (2008). "Decision support system for manufactured housing facility layout.”, J. Arcit. Eng., 14(2), 36-46.

Hosein Taghaddos, Ulrich Hermann, Simaan AbouRizk, Yasser Mohamed. (2014) "Simulation based multiagent approach for scheduling modular construction”, J. Comput. Civ. Eng. 28:263274.

Jeong,J. G., Hastak, M., and Syal,M. (2006). "Supply chain simulation modelling for the manufactured housing industry.” J. Urban Plann. Dev., 132(4), 217-225.

Kim, J. (2007), “An investigation of activity duration input modelling by duration variance ratio for simulation-based construction scheduling”, PhD thesis, Rutgers The State University of New Jersey - New Brunswick, New Brunswick, NJ.

Kumanan, S., Jegan Jose, G., Raja, K. (2006). "Multi-project scheduling using an heuristic and a genetic algorithm.” Int. J. Adv. Manuf. Technol., 31(3-4), 360-366.

M. Moghadam, M. Al-Hussein, S. Al-Jibouri, A. Telyas. (2012) "Post simulation visualization model for effective scheduling of modular building construction”, Can. J. Civ. Eng. 39: 1053-1061

Mohamed, Y., Borrego, D., Francisco, L., Al-Hussein, M., Abourizk, S., and Hermann, U. (2007). "Simulation-based scheduling of module assembly yards: Case study." Eng., Constr. Archit. Manage., 14(3), 293-311.

Mohanty, R. P., and Siddiq, M. K. (1989). "Multiple projects-multiple resources-constrained scheduling: Some studies.” Int. J. Prod. Res., 27(2), 261-280.

Mohsen, O.M., Knytl, P.J., Abdulaal, B., Olearczyk, J., and Mohamed, A.-H. (2008). "Simulation of modular building construction." Proc., Winter Simulation Conf., IEEE, Piscataway, NJ,2471-2478.

Nasereddin, M., M. Mullens, and D. Cope. 2007. Automated simulator development : A strategy for modelling modular housing production. Automation in Construction, 6(2): 212-223

Noh, hong woo, (2008). "Process Planning and Scheduling in Job Shop with Multiple Work Centers.” MS thesis, Soongsil University, Korea

Odeh, A. M. (1992), “CIPROS: knowledge-based construction integrated project and process planning simulation system”, PhD thesis, University of Michigan, Ann Arbor, MI.

Oguz, O., and Bala, H. (1994). "A comparative study of computational procedures for the resource constrained project scheduling problem.” Eur. J. Oper. Res., 72(2), 406-416.

Park, Jae sik, 2007, A Study of the Modular System of Construction to Build Defense Bachelor Officers’ Quarters, PhD thesis, Mokwon University, Korea

Payne, J.H., 1995. Management of multiple simultaneous projects: a state-of-the- art review. International Journal of Project Management 13 (3), 163-168.

Seren Ozmehmet Tasan, (2008). “A Riority-based Genetic Algorithm Approach for Solving Multiple Alternative Project Scheduling Problems with Resource Constraints and Variable Activity Times.” IEEE, 2537-2532.

Taghaddos, H., AbouRizk, S. M., Mohamed, Y., and Hermann, R. (2009). "Integrated simulation-based scheduling for module assembly yard.” Proc. Construction Research Congress 2009, ASCE, Reston, VA, 1270-1279.

Vercellis, C. (1994). "Constraned multi-project planning problem: A Lagrangean decomposition approach.” Eur. J. Oper. Res., 78(2), 267-275.

Wang, P. (2006), "Production-based large scale construction simulation modelling”, PhD thesis, University of Alberta, Edmonton. 
Yu, H., M. Al-Hussein, and R. Nasseri. 2007. Process Flowcharting and Simulation of house structure components production process. Proceedings of th 2007 Winter Simulation Conference, ed S. G. Henderson, B. Biller, M.-H. Hsieh, J. Shortle, J. D. Tew, and R.R. Barton, 2066-2072. 
